Running head: INTENTION OFFLOADING AND AGEING

Age differences in strategic reminder setting and the compensatory role of metacognition Chiara Scarampia and Sam J. Gilberta

anstitute of Cognitive Neuroscience, University College London, United Kingdom

Draft version 1.2, 30/06/2020. This paper has not been peer reviewed. Please do not copy or cite without author's permission.

Author Note

Chiara Scarampi and Sam J. Gilbert, Institute of Cognitive Neuroscience, University College London, United Kingdom.

This work was supported by the Economic and Social Research Council (ESRC) under Grant ES/N018621/1. The authors declare that they do not have competing interests.

Correspondence concerning this article should be addressed to Chiara Scarampi, Institute of Cognitive Neuroscience, 17 Queen Square, London WC1N 3AZ, United Kingdom. E-mail: c.scarampi@ucl.ac.uk 


\begin{abstract}
Previous research has shown that older adults can have difficulty remembering to fulfil delayed intentions. In the present study, we explored whether age differences in prospective memory are affected when participants are permitted to set reminders to help them remember. Furthermore, we examined whether metacognition can influence the use of such strategies and help older adults compensate for age-related memory decline. In this preregistered study $(\mathrm{N}=88)$ we administered a computerised task requiring a sample of older (aged 65-84) and younger (aged 18-30) participants to remember delayed intentions for a brief period, manipulating the possibility of setting reminders to create an external cue. Performance of the older group was significantly poorer than the younger group. Moreover, older adults were overconfident in their memory abilities and did not fully compensate for impaired performance, even when strategic reminder-setting was permitted. These findings suggest that older adults possess limited metacognitive knowledge about their prospective memory limits and may not fully utilise cognitive offloading strategies to compensate for memory decline.
\end{abstract}

Keywords: Ageing, Prospective Memory, Cognitive Offloading, Reminders, Delayed Intentions, Metacognition, Confidence, Metamemory 


\section{Age differences in strategic reminder setting and the compensatory role of metacognition}

Prospective memory refers to the ability to remember a planned intention and carry out specific tasks at a particular moment in the future (Einstein \& McDaniel, 1990; Ellis, 1996). Everyday examples of prospective memory are remembering to take medication according to a schedule or to attend a meeting at a specific time. In order to relieve the burden of intention maintenance in internal memory and increase the likelihood of remembering to carry out these delayed intentions, we can rely on the external environment. For instance, this may involve setting a reminder such as an alarm or calendar alert or keeping a diary listing the upcoming appointments. The use of physical actions to create external triggers for delayed intentions has been referred to as intention offloading (Gilbert, 2015a, 2015b). The present study provides a systematic investigation of the effect of ageing on the use of the external reminders for remembering delayed intentions. We also examined the potential role of metacognitive evaluations in compensating for age-related declines in unaided memory ability.

\section{Prospective memory and ageing}

Three decades of research have shown that performance on prospective memory tasks in the laboratory declines in older age (Ihle et al., 2013; Kliegel et al., 2008; Uttl, 2008). However, closer inspection of the literature reveals high variability in age-related differences across studies. Whereas some researchers found significant declines in older adults' prospective memory performance compared to their younger counterparts (Maylor, 1996; Park et al., 1997), other studies suggested that prospective memory ability does not decline with ageing (Einstein \& McDaniel, 1990).

This variability might be explained by age-related changes in the underlying processes. For example, one factor which seems to partly explain age deficits in prospective 
memory is working memory (Rose et al., 2010). Rose and colleagues (2010) presented evidence that when a task places greater demands on attentional resources and requires a monitoring strategy (e.g., when performing more irregular, non-repeated tasks), working memory accounts for prospective memory performance. Other aspects of executive function that may explain age differences in prospective memory are shifting (i.e., the capacity to switch attention from one task to another) and inhibition (i.e., the ability to refrain from performing a particular action, or to ignore distracting information; Schnitzspahn et al., 2013). Furthermore, research has shown that age differences in prospective memory are accentuated when the task requires strategic monitoring to detect the cue (i.e., when the prospective memory cue is not associated with the ongoing task; Kliegel et al., 2008) and when there is a high maintenance load (Ballhausen et al., 2017). On the other hand, the literature has established that age differences in prospective memory are reduced when attentional resources are directed toward the prospective memory task, such as when the importance of the prospective memory task is higher or emphasised (Hering et al., 2013) or when the absorption by the ongoing task is lower (Schnitzspahn et al., 2011).

In addition to these cognitive and task-inherent factors, age differences in prospective memory are further influenced by the setting in which the prospective task is performed. Specifically, previous studies have documented the so-called "age-prospective memory paradox" (Aberle et al., 2010); that is, the prospective memory deficits associated with ageing are not usually seen in naturalistic tasks, where older adults' performance can even surpass younger adults' performance (Schnitzspahn et al., 2011; Uttl, 2008). A potential explanation tested in the current experiment is that this paradox can be explained, at least in part, by an increased general tendency of older adults to use external memory aids, which in previous studies have only been available in naturalistic tasks (see Maylor, 2008; Phillips et al., 2008). 


\section{Intention offloading}

A key question is whether older adults are able to use strategies to compensate for impaired prospective memory abilities. The scaffolding theory of ageing and cognition proposed by Park and Reuter-Lorenz (2009) posits that older adults can maintain a high level of cognitive success despite neural and functional deterioration due to the engagement of a scaffolding mechanism: a circuit that provides supplementary, complementary, and alternative ways to succeed in a cognitive endeavour (see also Reuter-Lorenz \& Park, 2014, for a revised model incorporating the influence of life-course factors on compensatory scaffolding). As suggested by Baltes and Baltes (1990), successful cognitive ageing depends upon a general process of adaptation based on the optimisation of internal cognitive processes (e.g., through mnemonic strategies) and the use of the external environments and technology as compensatory mechanisms for the lost behavioural capacities (i.e., through cognitive offloading strategies such as making lists or set reminders). Furthermore, it has been suggested that ageing is associated with an increased reliance on environmental support across a range of tasks beyond those involving prospective memory (Lindenberger \& Mayr, 2014). Accordingly, it seems plausible to hypothesise that while cognitive offloading strategies can be used by individuals of any age, they can be particularly beneficial for older adults to compensate for age-related declines in cognitive abilities and contribute to a successful ageing.

In a first attempt to investigate the hypothesis of a reduced memory impairment when individuals are allowed to use compensatory aids, Einstein and McDaniel (1990) compared prospective memory between young and older participants and manipulated whether they were allowed to spontaneously create an external memory aid. Younger and older participants did not differ in the nature of the aids developed and equally benefitted from 
their use. In another study investigating spontaneous use and benefits of external memory aids in older and younger adults, Schryer and Ross (2013) found that the two groups were equally likely to use a memory aid when they were allowed to do so. Nevertheless, older adults benefitted more than their younger counterparts from the availability of memory aids. Further evidence on age differences in the use of external strategies comes from self-report measures. Previous studies have shown that older adults report making a greater use of memory-aiding strategies than their younger counterparts (Bolla et al., 1991; Bouazzaoui et al., 2010; Loewen et al., 1990; Lovelace \& Twohig, 1990) whereas the use of internal strategies (e.g., forming associations) decreases with age, both in daily life (Bouazzaoui et al., 2010; Hultsch et al., 1987; Loewen et al., 1990) and during laboratory memory-encoding tasks (Naveh-Benjamin et al., 2007). A possible interpretation of this result is that the effectiveness of internal memory strategies is affected by the age-related decline in attention allocation and attentional resources (Masumoto et al., 2011). However, not all studies found an effect of ageing on the use of internal strategies for memory tasks (see Kuhlmann \& Touron, 2012; Touron et al., 2010).

Older adults might be able to perform tasks adequately when they have the opportunity to use external memory aids that compensate for age-related unaided memory declines in naturalistic settings. For instance, Masumoto and colleagues (2011) found that older adults reported a higher use of external memory aids in complex prospective memory tasks that require output monitoring and the use of external (but not internal) memory strategies enhanced prospective memory performance. Further studies investigating the relationship between cognitive strategy use and prospective memory performance in older adults found that increased utilization of external memory strategies was significantly associated with higher performance accuracy (Aronov et al., 2015; Weakley et al., 2019). In an online study, Gilbert (2015a) found an increased use of offloading strategies in older 
adults. However, most participants in the study were under 60 years old and due to the little information about participants' demographics available from this source, it is unclear to what extent participants in this experiment were matched on background variables such as IQ and education. The current experiment aimed at providing a more rigorous test of the effect of age on intention offloading in a lab-based study and investigate whether providing the opportunity to use an intention offloading strategy can reduce age differences in memory accuracy. We did this by adapting the intention offloading paradigm used by Gilbert (2015a) and comparing performance in a sample of younger and older adults. Performance was examined in a $2 \times 2$ within-subject design crossing intention offloading (permitted / not permitted) and memory load ( 1 item, 3 items). This allowed us to test age differences in the use of external reminders and their impact upon memory performance.

\section{The role of metacognition}

One of the factors contributing to the decision whether to use cognitive offloading strategies is metacognition; i.e., the ability to monitor and control our current performance on a cognitive task (Dunlosky \& Metcalfe, 2009; T. O. Nelson \& Narens, 1990). Research has shown that individuals decide whether to offload to-be-remembered information based on metacognitive evaluations of their unaided ability (Dunn \& Risko, 2016; Risko \& Gilbert, 2016). For example, Gilbert (2015b) found that the likelihood of setting reminders in a prospective memory task was based on how confident participants were that they would fulfil the delayed intentions, regardless of objective memory ability (see also Cherkaoui \& Gilbert, 2017).

Previous evidence has also suggested that the decision to offload to-be-remembered information onto the environment depends on memory load. Tasks with a higher memory load may increase the perceived difficulty of remembering and lead individuals to use cognitive offloading strategies. Accordingly, Gilbert (2015a) found that participants set more 
reminders when they had to remember three items compared to one item and Risko and Dunn (2015) found that in a short-term memory task, the use of offloading strategies was related to the number of to-be-remembered items. Similarly, Hu, Luo, and Fleming (2019) asked participants to learn word pairs and found that participants adaptively used offloading strategies for the most difficult items. A computational model further indicated a negative correlation between participants' beliefs about the boost in performance they would gain from the offloading strategy and evaluations of their memory ability. Additionally, metacognitive evaluations of their own memory abilities guided participants' decisions to use offloaded information during the retrieval phase. Altogether, these results confirm that individuals' confidence judgements about their own memory are crucial to determine whether they will use an external memory aid and highlight the strong association between cognitive offloading and metacognitive evaluation about memory performance.

Further evidence for a close link between cognitive offloading and prospective metamemory comes from an experiment by Boldt and Gilbert (2019) showing that individuals are more likely to set reminders when they have low confidence in their memory abilities, independently of whether they are instructed to use an offloading strategy or they spontaneously develop one. These findings suggest that people draw on metacognitive knowledge about their own memory and available external aids to choose the strategy they believe will lead to higher memory performance.

\section{Metacognition and ageing}

Since our memory capabilities change as we get older, the ability to accurately monitor and control our remembering and the fulfilment of delayed intentions has important theoretical and practical implications. Nevertheless, whereas metacognition has received substantial attention in the retrospective memory literature, relatively little is known about its role for age differences in prospective memory and the existing research has provided a 
complex picture of preservation and deficits which depends on methodology, task, and memory domain.

Age-related changes in memory are often accompanied by self-reported observations of this phenomenon. Older adults are aware that memory performance changes with ageing (Hertzog \& Hultsch, 2000) and they are at risk of experiencing performance-degrading stereotype threat during memory assessments - i.e., even subtle cues referring to age-related memory impairment can diminish performance, also in prospective memory tasks (Zuber et al., 2019). Previous studies have shown that negative views of age-related memory changes (i.e., stereotypes about ageing) are associated with increased reporting of memory failures (Jennings \& Darwin, 2003) and poorer performance at memory tests (Chasteen et al., 2015). Negative conceptions about getting older can impact upon both older adults' objective performance and their confidence in their own memory abilities. Nevertheless, the relationship between metacognition and prospective memory performance may depend on the type of task. For example, Masumoto and colleagues (2011) found that reduced accuracy in a prospective memory task was associated with reporting of memory failures in a time-based condition but not in an event-based condition.

Previous research in the prospective memory domain has found a significant negative correlation between age and relative metacognitive accuracy (i.e., the ability to discriminate between correct and incorrect responses; $\mathrm{Ng}, 2017$ ) and shown that in some situations older adults may initially overestimate their ability to remember information (e.g., Cauvin et al., 2019). Nevertheless, older adults might be better able to evaluate their cognitive functioning in everyday prospective memory tasks, which are highly familiar to them and in which they typically perform well (Ballhausen et al., 2019). Indeed, metacognitive judgements are associated with age benefits in naturalistic prospective memory tasks (Devolder et al., 1990; Schnitzspahn et al., 2011). Since older adults have a lifelong experience in naturalistic 
prospective memory tasks, they might be able to provide more accurate evaluations of their performance in those settings and select appropriate strategies to perform optimally. In laboratory tasks, however, older adults do not show better metacognitive monitoring (Schnitzspahn et al., 2011). In a recent study, Cauvin and colleagues (2019) found that, at the item-level, younger adults were fairly accurate in the prospective component of prospective memory (i.e., remembering that something has to be done), whereas older adults were overconfident. By contrast, for the retrospective component of prospective memory (i.e., remembering what to do), young and older adults were equally accurate and slightly overconfident.

Recognising the need of using cognitive offloading strategies and knowing how to successfully use them are relevant metacognitive skills. Older adults may be more aware of their need to use external strategies to support their memory. Accordingly, another aim of the current study was to investigate whether age-differences in intention offloading relate to age differences in metacognitive confidence. This would allow us to understand the potential role of metacognition in compensation for age-related cognitive decline in prospective memory.

\section{Aims of the current study}

We investigated whether the availability of an intention offloading strategy affected age differences in participants' ability to remember delayed intentions. We evaluated the evidence for the hypotheses that 1) older adults would perform relatively poorly in the unaided condition, but 2) this impairment would be reduced or eliminated when offloading was allowed. We also expected 3) older adults to use the intention offloading strategy more often than their younger counterparts when given a free choice.

Furthermore, since metacognition has been shown to play an important role in triggering intention offloading behaviour, we investigated whether younger and older participants differed in their metacognitive evaluations of their own memory abilities. We 
hypothesised that 4) the effect of age on intention offloading would be partially or fully mediated by age differences in metacognitive confidence (i.e., age differences in intention offloading would be reduced or eliminated after controlling for confidence).

Besides looking at age differences in intention offloading in a laboratory delayed intention task, we collected some self-reported measures of prospective memory abilities as well as measures of the use of internal mnemonic strategies and external memory aids. This allowed us to perform an exploratory comparison between intention offloading in a laboratory task and self-reported intention offloading behaviour in real life.

Before commencing data collection, we preregistered our hypotheses, sample size, experimental procedure, participant exclusion criteria, and analysis plan (https://osf.io/4utrs/).

\section{Method}

\section{Participants}

A total of 44 younger adults (age range $18-30, M=23.5$ years, $S D=3.3 ; 30$ female) and 44 older adults (age range 65-84, $M=73.2$ years, $S D=5.6 ; 31$ female) were recruited from the local community via flyers and advertisement on newsletters and forums. An additional 20 participants were tested but excluded as a result of our pre-registered exclusion criteria (see below).1

Ethical approval was received from the UCL Research Ethics Committee (1584/002) and participants provided informed consent before participating in the study.

Participation was restricted to native English speaker volunteers aged 18-30 years (younger adults) or 65+ years (older adults) with no history of major neurological and psychological conditions. Participation was not allowed to individuals who had already taken part in similar studies in our laboratory to ensure a fresh sample of participants. 
A statistical power analysis was performed with $\mathrm{G}^{*}$ Power 3.1 for sample size estimation. We based the computations on the results of a meta-analysis conducted by Uttl (2008) of research comparing younger and older adults' performance in prospective memory tasks. The size of the age effect found for performance of prospective memory tasks most comparable to the present paradigm (i.e., lab-based, event-cued tasks focusing on vigilance) was $d=0.61$. With an alpha $=.05$ and power $=0.80$, the projected sample size needed for detecting an age effect on prospective memory accuracy is $N=88$ for the simplest between group comparison (44 younger and 44 older). Accordingly, data collection was terminated after 88 usable datasets.

Participation took approximately 60 minutes, for which participants were paid $£ 7.50$.

\section{Measures}

Intention offloading task (Gilbert, 2015a). In each trial of this computerised task, participants had to drag a series of 10 numbered circles in ascending order $(1,2,3$, etc.) to the bottom of a box. Each time a circle was dragged to the bottom, it disappeared, leaving the other circles on the screen. After the 10th circle disappeared, the screen was cleared and a new trial began (see Figure 1 for a schematic illustration of the task and visit http://www.ucl.ac.uk/sam-gilbert/demos/circleDemo.html for a demonstration). At the beginning of each trial, participants were instructed that either one or three of these circles had to be dragged to a different location when reached in the sequence (i.e., left, right, or top of the box). This led to the formation of delayed intentions to perform particular actions when they encountered prespecified cues, although participants could produce a standard ongoing response (i.e., dragging the circle to the bottom of the box) if they forgot.

The task also permits participants to drag target circles next to the instructed location at the beginning of the trial (i.e., before dragging circle 1 to the bottom of the box). For example, if a participant was told to drag circle number 10 to the left, they could drag this 
circle next to the left side of the box at the beginning of the trial. This strategy allows participants to offload intentions, as the position of these circles on screen acts as a reminder of the prospective task when they are reached in the sequence, without the need of mentally rehearsing the delayed intention(s) while dragging the other circles. An everyday analogy would be leaving an object by the front door so that you remember it when leaving the house tomorrow. Participants were informed of this strategy, and when it was permitted that had a free choice whether to set reminders in this way or remember the intention using their own memory. [Figure 1 approximately here]

In order to increase the difficulty of the task and reduce the possibility of ceiling effects, the intention offloading task was intermixed with an arithmetic-verification test. That is, during each trial of the intention offloading task, participants additionally received a distracting arithmetic question, via a pop-up box (using the same procedure as Gilbert, 2015a). This occurred immediately after dragging one of the nontarget circles to the bottom of the box, at a position in the sequence randomly selected between the first circle and the circle immediately before the first target.

The experiment code needed to replicate the current study can be found by visiting the first author's account on Open Science Framework (https://osf.io/3f52c/).

Manipulation. The experiment consisted of 20 experimental trials, divided in two phases and the key element of the study was the manipulation of intention offloading, memory load (i.e., number of target circles), and age groups. More precisely, at the beginning of the experiment, participants were randomly assigned to one of two conditions: No Reminders or Optional Reminders. In phase 1, participants in the no-reminder condition were asked to complete the intention offloading task relying on their internal memory only, whereas participants in the optional-reminder condition were able to choose whether to rely on their internal memory or complete the task making use of reminders. A second phase of 
the experiment followed immediately after the first and was the opposite of phase one. In each phase there were 5 trials with 1 target circle and 5 trials with 3 target circles, presented in randomised order.

Offloading proportion. As in Gilbert (2015a), the offloading proportion (i.e., the proportion of reminders used by participants) was operationalised as the difference between the proportion of target circles moved before reaching their position in the ongoing task and the proportion of nontarget circles clicked out of sequence. The rationale for this is to obtain a measure of offloading behaviour that is corrected for any tendency to accidentally select wrong circles and move nontarget circles before their turn in the sequence.

Metacognitive judgement scale. In addition to the delayed intention task, we measured metacognitive beliefs. After completing the practice trials, both with unaided memory ability and with reminders, participants were asked to rate their confidence in their ability to correctly execute intentions in the upcoming task by moving a slider ranging from $0 \%$ (none of the target circles correctly remembered) to $100 \%$ (all target circles correctly remembered) for each experimental condition. This procedure resulted in 4 confidence estimates per participant: 1 Target/No Reminders prediction, 3 Targets/No Reminders prediction, 1 Target/Optional Reminders prediction, and 3 Targets/Optional Reminders prediction.

Patient health questionnaire (PHQ-9). The PHQ-9 (Kroenke et al., 2001) is the depression module of the Patient Health Questionnaire, a self-administered version of the PRIME-MD diagnostic instrument for common mental disorders. It is a test for making criteria-based diagnoses of depressive disorders. It asks participants to rate the presence of depressive symptoms in the past 2 weeks. As a severity measure, the PHQ-9 score can range from 0 to 27, since each of the 9 items can be scored from 0 (not at all) to 3 (nearly every day). 
Metacognitive prospective memory inventory (MPMI-s). The short version of the MPMI (Rummel et al., 2019) is a questionnaire for the assessment of self-reported prospective memory abilities and strategy use. It consists of three scales with eight items each. The Prospective Memory Ability (PMA) scale measures individuals' perceptions of their own prospective memory abilities (e.g., "If I've borrowed something from someone for a while, I remember to give it back to that person the next time we see each other"). Half of the items are reverse-coded and refer to prospective forgetting rather than prospective remembering. The PMSi scale assesses how frequently individuals use internal prospective memory strategies to help themselves remembering (e.g. "In my mind I make a list of things that I still have to complete"). The PMSe scale assesses the frequency with which individuals use external prospective memory strategies to better remember their intentions (e.g., "I write shopping lists"). Each item is rated on a 5-point Likert scale ranging from 1 (rarely) to 5 (often).

Need for cognition scale (NCS). The NCS (Cacioppo et al., 1984) consists of 18 items measuring individual differences in the tendency to engage in and enjoy thinking (e.g., "I really enjoy a task that involves coming up with new solutions to problems"). High scores reveal individuals' preferences for effortful cognitive activities. Responses are given on a 5point Likert scale ranging from 1 (extremely uncharacteristic of me) to 5 (extremely characteristic of me).

Montreal cognitive assessment (MoCA). The MoCA (Nasreddine et al., 2005) is a brief cognitive screening tool for detecting mild cognitive impairment and Alzheimer's disease. The 30 items assess multiple cognitive domains ranging from short-term memory to visuospatial abilities, attention, and executive functioning. Higher scores indicate better cognition, with a maximum score of 30 . 
National adult reading test (NART). The NART (H. E. Nelson \& Willison, 1991) is a widely used task to estimate premorbid IQ. It comprises a list of 50 English words with orthographically irregular spellings (e.g., "gaoled" or "drachm") that the participant has to read aloud. Points are awarded for correct pronunciation. The test was given as a measure of crystallised verbal intelligence.

\section{Raven's standard progressive matrices (RSPM short form A). The RSPM} instrument (Raven et al., 1998) is a multiple-choice test to assess non-verbal abstract and cognitive functioning. In the test, a candidate is presented with a number of matrices of geometric shapes, with one piece missing. The candidate has to choose from a set of possible answers which one completes the pattern in each matrix. The abbreviated 9-item version of the test (RSPM-form A; Bilker et al., 2012) was used as a proxy of fluid intelligence. Scores are integers indicating the number of correct responses.

\section{Procedure}

Participants first performed the intention offloading task on a tablet Samsung Tab A 10.1 , which had a resolution of $1280 \times 800$ pixels. Next, they completed the questionnaires on paper in the following order: patient health questionnaire-9, metacognitive prospective memory inventory, and need for cognition scale. Finally, they engaged in the Montreal cognitive assessment, the national adult reading test, and the Raven's standard progressive matrices (short form A). A total of 20 participants were excluded and replaced as a result of the following pre-registered exclusion criteria: $\geq 10$ points at the PHQ-9 (10 participants); < 24 points at the MoCA (7 further participants); $\leq 80 \%$ accuracy in the arithmetic-verification test (3 further participants).

\section{Results}

We followed our pre-registered analysis plan, with one additional analysis (noted below). 
Mean arithmetic-verification accuracy was $98 \%$ for older adults and $99 \%$ for their younger counterparts.

\section{Objective Accuracy}

Objective accuracy (i.e., the proportion of targets correctly dragged to the instructed location rather than to the bottom of the square) was analysed with a three-factor mixed analysis of variance (ANOVA) including within-subject factors of offloading condition (no reminders, optional reminders) and memory load (1 target, 3 targets), and age group (young, older) as between-subject factor. Interaction effects were further explored using simple pairwise comparisons (see Table 1 for all inferential statistics). [Table 1 approximately here]

First, young participants $(M=91.7, S D=14.1)$ outperformed older adults $(M=84.6$, $S D=20.3)$. Second, performance was better in the 1-target $(M=92.0, S D=14.2)$ compared with the 3-target condition $(M=84.3, S D=20.1)$ and in the optional-reminder condition $(M$ $=91.8, S D=14.2)$ compared to the no-reminder condition $(M=84.5, S D=20.2)$.

Furthermore, results showed a significant interaction between age group and memory load: the age effect was observed at the higher but not the lower memory load (see Table 2 for inferential statistics). There was also an interaction between memory load and offloading condition: the effect of memory load was reduced, but not eliminated, when offloading was permitted (see Table 3 for inferential statistics). [Table 2 and Table 3 approximately here] The interaction between offloading condition and age was not significant, nor was the threeway interaction between age group, memory load and offloading condition. Therefore, permitting participants to set external reminders did not significantly reduce the effect of age on accuracy. Nevertheless, there was a trend towards a reduced age difference when offloading was permitted, so that the effect of age was significant when participants were forced to use their own memory but not significant when offloading was permitted (Table 3).

We also computed independent sample t-tests comparing younger and older 
participants separately by condition (see Table 4). [Table 4 approximately here] At the lower memory load, there was no significant difference in accuracy between younger and older participants, regardless of whether offloading was permitted. At the higher memory load, younger participants outperformed older participants, both when offloading was permitted and when it was not.

Altogether these results confirmed our first hypothesis that older adults would perform more poorly than their younger counterparts when they were asked to perform the task without using reminders. In terms of our second hypothesis that age effects would be reduced or eliminated when reminders were permitted, there was a nonsignificant trend towards reduced age effects when offloading was permitted. However, age effects were clearly not eliminated, seeing as they were observed at the higher memory load both when offloading was permitted and when it was not.

\section{Intention Offloading}

In order to test the hypothesis that older adults would set more reminders than their younger counterparts when given a free choice, we performed a mixed ANOVA with memory load (1 target vs. 3 targets) as within-subject factor and age group (younger vs. older) as between-subject factor. The analysis revealed a significant effect of memory load $\left(F(1,86)=42.53, p<.001, \eta_{\mathrm{p} 2}=.33\right)$, with more offloading in the 3-target than the 1-target condition (see Figure 2). [Figure 2 approximately here] The effect of age group was not significant $\left(F(1,86)=1.70, p=.196, \eta_{\mathrm{p} 2}=.02\right)$, against our prediction of higher offloading proportion in the older group. The interaction between memory load and age group was also not significant $\left(F(1,86)=1.05, p=.309, \eta_{\mathrm{p} 2}=.01\right)$.

As a follow-up analysis, we also ran independent sample t-tests to compare the offloading proportion for younger and older adults within each memory-load condition (i.e., separately for 1 and 3-target trials). The two groups did not significantly differ in the 
frequency of reminder setting, either with one target (younger adults: $M=0.38, S D=0.45$; older adults: $M=0.53, S D=0.46 ; t(1,86)=1.52, p=.132, d=.32)$, or with three targets (younger adults: $M=0.68, S D=0.41$; older adults: $M=0.74, S D=0.38 ; t(1,86)=0.77, p=$ $.442, d=.16)$.

We also performed paired t-tests comparing the offloading proportion between 1target and 3-target trials, separately for each age group. Both younger adults $(t(1,43)=5.14, p$ $<.001, d=.70)$ and older adults $(t(1,43)=4.05, p<.001, d=.52)$ set significantly more reminders in the 3-target condition.

\section{Incongruency between performance and strategy selection}

In the analyses reported above, older adults showed impaired unaided performance of the task in the 3-target condition compared to younger participants but no significant differences in their use of reminders. That is, despite the impaired performance of the task, older adults did not show a commensurate increase in compensatory offloading behaviour when it was permitted. We decided to follow this up with a direct statistical test to investigate evidence for a disconnect between performance and strategy selection (see Cherkaoui \& Gilbert, 2017, for the same analytic approach). Unlike the other analyses presented above and below, this was not part of our pre-registered analysis plan.

The incongruency between performance and strategy selection was formally tested with an age group (younger vs. older adults) x measure (target accuracy vs. intention offloading) ANOVA. This analysis was restricted to the 3-target condition only, seeing as this was the only condition where accuracy differed between the age groups. In order to make objective accuracy and intention offloading comparable measures, they were converted into $z$ scores by subtracting the population mean and dividing by the standard deviation.

Furthermore, the $z$ scores of intention offloading were reversed, converting positive values to negative and vice versa. This is because compensation implies an inverse relationship 
between accuracy and offloading - i.e., reduced unaided accuracy should yield increased offloading. Without this step, appropriate compensatory offloading would yield an interaction between the two measures.

The ANOVA showed a significant interaction between age group and measure $\left(F(1,86)=4.47, p=.037, \eta_{\mathrm{p} 2}=.05\right)$. This reflected a significant difference between younger and older adults in target accuracy $(t(1,86)=3.72, p<.001, d=.79)$ but not in offloading behaviour $(t(1,86)=0.77, p=.442, d=.16)$. Therefore, despite impaired unaided performance of the task, older adults did not show a commensurate increase in strategic reminder setting.

\section{Metacognitive Bias}

In order to study how well calibrated participants' performance predictions were to their objective accuracy, metacognitive bias was calculated as the discrepancy between predicted and objective accuracy. A positive value would indicate overconfidence and a negative value underconfidence (see also Tables 1-3 for full analyses of participants' metacognitive predictions, without subtracting objective accuracy). Figure 3 shows the results of one-sample t-tests comparing each metacognitive bias score against zero, separately for each condition and age group. [Figure 3 approximately here] These bias scores were evaluated in a memory load $\mathrm{x}$ offloading condition $\mathrm{x}$ age group ANOVA (see Table 1 for inferential statistics). The results showed a significant two-way interaction between age group and memory load: older adults became increasingly confident (relative to objective accuracy) at the higher memory load $\left(F(1,43)=3.04, p=.088, \eta_{\mathrm{p} 2}=.07\right)$, whereas younger adults became less confident $\left(F(1,43)=2.20, p=.146, \eta_{\mathrm{p} 2}=.05\right)$. There was also an interaction between age group and offloading condition: older adults had higher confidence (relative to objective accuracy) in the no-reminder than the optional-reminder condition $\left(F(1,43)=12.88, p<.001, \eta_{\mathrm{p} 2}=.23\right)$, whereas younger adults had a similar metacognitive 
bias in the two conditions $\left(F(1,43)=.01, p=.915, \eta_{\mathrm{p} 2}<.01\right)$. Overall, as shown in Figure 3 , older adults were overconfident in the no-reminder condition and underconfident (at least at the lower memory load) when reminders were permitted. By contrast, younger adults did not show significant metacognitive bias in any condition.

\section{Reminder Setting and Metacognition}

In order to test the hypothesis that any effect of age on reminder setting is mediated by age differences in metacognitive confidence, we ran a mediation analysis using PROCESS 3.4 for SPSS (Hayes, 2018), performed both collapsing over memory load conditions and separately for each condition. We expected to find a nonsignificant direct effect and a significant indirect effect of age group on reminder setting, mediated by metacognitive judgements. Against the original prediction, both the direct effect of age group on reminder setting (1-target condition: $b=.08, p=.114 ; 3$-target condition: $b=.03, p=.54$; collapsed across conditions: $b=.05, p=.192$ ) and its indirect effect mediated by metacognitive confidence $(1-$ target condition: $\mathrm{IE}=-.005,95 \% \mathrm{CI}=(-.037, .010) ; 3$-target condition: $\mathrm{IE}=$ $.007,95 \% \mathrm{CI}=(-.014, .027)$; collapsed across conditions: $\mathrm{IE}=.0002,95 \% \mathrm{CI}=(-.022, .017))$ were nonsignificant.

\section{Cognitive Abilities and Ageing}

We ran an independent sample t-test to compare younger and older participants' scores at the NART and Ravens' Matrices. Older adults performed significantly worse than younger adults in the Ravens' Matrices $(t(1,86)=3.92, p<.001, d=.84)$, but better than younger adults in the NART $(t(1,86)=7.01, p<.001, d=1.49)$. As expected, this suggests a decline in older adults' fluid intelligence and an age-related increase in crystallised intelligence. 


\section{Need for Cognition}

Next, we were interested in studying whether individual differences in the decision to set reminders were driven by a personal preference for internal forms of effort rather than one's own memory abilities. We ran a correlation between need for cognition and offloading proportion separately in the two groups, collapsing across 1-target and 3-target trials. The results didn't show any significant result (see Table 5). A regression model was also performed to study the relationship between need for cognition and offloading proportion controlling for objective and predicted unaided accuracy. The predictors explained only $12 \%$ of the variance for the older group $\left(R_{2}=.12, F(3,40)=1.75, p=.172\right)$ and less than $3 \%$ of the variance for the younger group $\left(R_{2}=.028, F(3,40)=.381, p=.767\right)$.

\section{Laboratory versus Real-Life Cognitive Offloading}

We performed an independent sample t-test to compare younger and older adults' self-reported prospective memory, as measured with the Prospective Memory Abilities subscale of the MPMI-s. Against our expectations, but in line with the results discussed above, older adults reported higher prospective memory abilities $(M=.85, S D=.11)$ than their younger counterparts $(M=.78, S D=.12 ; t(1,86)=2.78 ., p=.007, d=.59)$. Independent sample t-tests also showed that the two samples did not differ in the use of internal mnemonic strategies (younger adults: $M=.68, S D=.18$; older adults: $M=.70, S D=$ $.18 ; t(1,86)=0.52, p=.605, d=.11$ ) nor in the use of external memory aids (younger adults: $M=.73, S D=.16 ;$ older adults: $M=.76, S D=.17 ; t(1,86)=.81, p=.418, d=.17)$.

We also correlated self-reported use of external memory aids with offloading proportion in the intention offloading task separately for the two groups to study whether there was a correspondence between laboratory performance and self-reported real-life behaviour (see Table 5). The correlation was significant for the older adults $(r=0.30, p=$ $.048)$ and nonsignificant for the younger adults $(r=0.09, p=.555)$. The correlation between 
self-reported prospective memory ability and predicted accuracy in the intention offloading task was not significant (older adults: $r=-0.07, p=.652$; younger adults: $r=-0.02, p=.885$ ).

\section{Discussion}

The present study provided a systematic investigation of the effect of ageing on the use of the external reminders for remembering delayed intentions and the potential role of metacognitive evaluations in compensating for age-related memory decline. Although the adopted paradigm involved a brief retention interval (i.e., the time between intention encoding and its execution), results were consistent with previous studies investigating prospective memory over longer intervals and showing an impairment in older adults' performance (see Kliegel et al., 2008). Nevertheless, previous studies have shown that while older adults are typically impaired in laboratory-based prospective memory tasks, such deficits are not usually seen in naturalistic tasks (Schnitzspahn et al., 2011; Uttl, 2008). One possible contributor to this effect is an increased general tendency of older adults to use external memory aids, which in previous studies has mainly been tested in naturalistic tasks (see Maylor, 2008; Phillips et al., 2008 for a discussion). Therefore, the present study was designed to examine the effect of age on the propensity to set reminders for delayed intentions in a rigorous experimental task and investigate whether age-related differences in performance persisted when the use of a compensatory strategy was allowed.

The results showed that although older adults performed more poorly than their younger counterparts, they did not fully compensate for impaired performance by showing a commensurate increase in reminder setting when it was permitted. One potential explanation for our results is that older adults were overconfident in their unaided memory ability, so did not make as much use of the reminder-setting strategy as they might have done. Both younger and older adults in our sample were aware of the relative difficulty of the 3-target condition, as both groups predicted inferior performance on 3-target trials compared to 1- 
target trials and showed an increase in their use of reminders in the more difficult condition. Thus, participants in both groups understood the increased level of difficulty in the 3-target condition and translated this insight in strategic behaviour. This suggest that the lack of compensatory behaviour in the older group is not due to a lack of understanding of the benefit of using external reminders. Nevertheless, at the group level, older adults were overconfident in their unaided abilities and their performance predictions were less accurate than those of their younger counterparts. Similarly, older adults' evaluations of their prospective memory abilities in the MPMI measure were also more confident than younger participants. These findings are consistent with a recent study by Cauvin and colleagues (2019) showing an age impairment in both prospective and retrospective components of prospective memory and, in particular, overconfidence in the ability to remember that something has to be done. Accordingly, we found that older adults overestimated their ability to perform the task in the unaided condition.

A second possibility is that older adults differ from their younger counterparts in their metacognitive control; i.e., the ability to use their metacognitive knowledge to inform strategic behaviour (see McGillivray \& Castel, 2017, and references therein). This pattern of results was previously demonstrated in young children by Redshaw et al. (2018). Despite demonstrating metacognitive knowledge about the influence of task difficulty on task performance, the younger children in this study did not translate this knowledge into adaptive reminder-setting. Similarly, it is possible that in the present experiment, older participants did not compensate for reduced unaided accuracy because they did not fully translate their metacognitive insight about the difficulty of the 3-target condition into effective metacognitive control strategies such as reminder setting. This is in line with previous literature in the retrospective memory domain indicating that older adults often fail to use metacognitive control strategies even though they can be highly effective for them (see 
Hertzog, 2016, for a review). One corollary of this is that increasing older adults' awareness of age-related declines in memory may not be sufficient to maximise the use and effectiveness of compensatory strategies (see Cherkaoui \& Gilbert, 2017, for a related finding in individuals with autism spectrum conditions).

A final potential explanation of our findings comes from a motivational perspective. It is possible that older participants perceived the task as a way to have their memory assessed and the use of reminders as 'cheating'. As previously discussed, there is a wide spread belief that memory declines in old age (see Hummert, 2011, for a review) and ageing stereotypes have the potential to become self-fulfilling prophecies for older individuals (Kornadt \& Rothermund, 2012; Levy \& Leifheit-Limson, 2009). These can lead to increased health concerns such as dementia worry, i.e., an anxiety-related response to the possibility of developing dementia (Molden \& Maxfield, 2017). It is possible that older adults selfselecting to take part in this study were particularly susceptible to these worries and behaved in such a way to test their unaided memory. The instructions given to participants in this study were straightforward: on each trial, they were told to produce a particular behaviour (e.g., 'please drag 5 to the left'). It was not specified that the purpose of the experiment was to assess how younger and older adults differed in the use of intention offloading strategies. Nevertheless, it is conceivable that compared to their younger counterparts, older adults differed in their motivation to perform the memory task and formed a different model of the implicit task demands. One way to test this hypothesis would be to give more explicit instructions regarding the aim of the experiment, to see whether this affects participants' willingness to use strategies to improve task performance.

Another potential avenue for future research is the investigation of age-differences in the adoption of different strategies. In a recent study using a variation of the task used here, Scarampi and Gilbert (2020) found that participants were biased to repeat whichever strategy 
they had previously used to perform the task. Previous studies have shown that individuals become more rigid in later adulthood (Lemaire et al., 2004; Lemaire \& Lecacheur, 2001) and individual characteristics such as rigidity might strengthen the bias towards the repeated application of a previously implemented strategy (Schillemans et al., 2012). Hertzog and colleagues (2019) found that older adults use a number of external memory aids making them part of complex routines and habits. Further delineating how age impacts upon the perseveration effect and how to build effective strategies into older adults' daily life is an important direction for further research.

One of the aims of the current study was to perform an exploratory comparison between intention offloading in a laboratory task and self-reported intention offloading behaviour in real life. The results indicated a correspondence between older adults' reported use of external compensatory strategies and reminder setting in the task. These findings provided further evidence that the present experimental paradigms can be related to the fulfilment of naturalistic intentions embedded within everyday activities.

Overall, the above findings have important implications for the design of guidelines and interventions aimed at promoting optimal use of external memory aids in older adults in order to support behavioural independence and health-related behaviours such as remembering to take medications. Furthermore, the results support previous research highlighting the relevance of taking into account the interplay between metacognition and the use of offloading strategies in old age (Castel et al., 2012). The results also add to the literature pointing to the relevance of interventions aimed at restructuring metacognitive knowledge about one's own memory abilities and age stereotypes about memory (e.g., West et al., 2008). Previous studies have shown that trainings based on metacognitive approaches to improve self-regulation have great benefits for assisting individuals compensating for agerelated memory deficits and optimising their everyday memory functioning (e.g., Dunlosky et 
al., 2011; Hertzog \& Dunlosky, 2011). Interventions can be designed to address older adults' tendency to overconfidence and memory illusions by helping them discriminate information they can remember from easy-to-forget information and adopt effective strategies accordingly.

Although the current study required participants to remember to execute an intention after a delay, as in standard experimental tasks, the duration of this delay period was much shorter than standard prospective memory paradigms (e.g., Einstein \& McDaniel, 1990; Graf \& Uttl, 2001, for discussion; Smith, 2003). As a consequence, it is unclear whether similar results would be found in tasks with a longer retention interval. Further research could investigate whether the results of the current experiment hold in tasks conducted over a longer time scale and when the use of reminders or other offloading strategies is habitual (cf. Hertzog et al., 2019), rather than a novel strategy (as in the present study).

In summary, our findings point to an impairment of memory ability in older adults and show that older adults do not necessarily compensate fully for this when they are able to. One potential explanation for this is an inaccurate metacognitive evaluation of unaided memory abilities, and/or a failure to translate these metacognitive evaluations into strategic reminder setting. This suggests that metacognitive interventions might improve prospective memory performance in older adults. 


\section{References}

Aberle, I., Rendell, P. G., Rose, N. S., McDaniel, M. A., \& Kliegel, M. (2010). The age prospective memory paradox: Young adults may not give their best outside of the lab. Developmental Psychology, 46(6), 1444-1453. https://doi.org/10.1037/a0020718

Aronov, A., Rabin, L. A., Fogel, J., Chi, S. Y., Kann, S. J., Abdelhak, N., \& Zimmerman, M. E. (2015). Relationship of cognitive strategy use to prospective memory performance in a diverse sample of nondemented older adults with varying degrees of cognitive complaints and impairment. Aging, Neuropsychology, and Cognition, 22(4), 486-501. https://doi.org/10.1080/13825585.2014.984653

Ballhausen, N., Hering, A., Rendell, P. G., \& Kliegel, M. (2019). Prospective memory across the lifespan. In J. Rummel \& M. A. McDaniel (Eds.), Prospective Memory (pp. 135156). Routledge. https://doi.org/10.4324/9781351000154-9

Ballhausen, N., Schnitzspahn, K. M., Horn, S. S., \& Kliegel, M. (2017). The interplay of intention maintenance and cue monitoring in younger and older adults' prospective memory. Memory \& Cognition, 45(7), 1113-1125. https://doi.org/10.3758/s13421-0170720-5

Baltes, P. B., \& Baltes, M. M. (1990). Psychological perspectives on successful aging: The model of selective optimization with compensation. In P. B. Baltes \& M. M. Baltes (Eds.), Successful aging: Perspectives from the behavioral sciences. (pp. 1-34). Cambridge University Press. https://doi.org/10.1017/CBO9780511665684.003

Bilker, W. B., Hansen, J. A., Brensinger, C. M., Richard, J., Gur, R. E., \& Gur, R. C. (2012). Development of abbreviated nine-item forms of the Raven's standard progressive matrices test. Assessment, 19(3), 354-369. https://doi.org/10.1177/1073191112446655

Boldt, A., \& Gilbert, S. J. (2019). Confidence guides spontaneous cognitive offloading. 
Cognitive Research: Principles and Implications, 4(1), 45.

https://doi.org/10.1186/s41235-019-0195-y

Bolla, K. I., Lindgren, K. N., \& Bonaccorsy, C. (1991). Memory complaints in older adults: Fact or fiction? Archives of Neurology, 48(1), 61-64.

https://doi.org/10.1001/archneur.1991.00530130069022

Bouazzaoui, B., Isingrini, M., Fay, S., Angel, L., Vanneste, S., Clarys, D., \& Taconnat, L. (2010). Aging and self-reported internal and external memory strategy uses: The role of executive functioning. Acta Psychologica, 135(1), 59-66.

https://doi.org/10.1016/j.actpsy.2010.05.007

Cacioppo, J. T., Petty, R. E., \& Feng Kao, C. (1984). The efficient assessment of need for cognition. Journal of Personality Assessment, 48(3), 306-307. https://doi.org/10.1207/s15327752jpa4803_13

Castel, A. D., McGillivray, S., \& Friedman, M. C. (2012). Metamemory and memory efficiency in older adults: Learning about the benefits of priority processing and valuedirected remembering. In M. Naveh-Benjamin \& N. Ohta (Eds.), Memory and aging: Current issues and future directions (pp. 245-270). Psychology Press.

Cauvin, S., Moulin, C. J. A., Souchay, C., Kliegel, M., \& Schnitzspahn, K. M. (2019). Prospective memory predictions in aging: Increased overconfidence in older adults. Experimental Aging Research, 45(5), 436-459. https://doi.org/10.1080/0361073X.2019.1664471

Chasteen, A. L., Pichora-Fuller, M. K., Dupuis, K., Smith, S., \& Singh, G. (2015). Do negative views of aging influence memory and auditory performance through selfperceived abilities? Psychology and Aging, 30(4), 881-893. https://doi.org/10.1037/a0039723

Cherkaoui, M., \& Gilbert, S. J. (2017). Strategic use of reminders in an 'intention offloading' 
task: Do individuals with autism spectrum conditions compensate for memory difficulties? Neuropsychologia, 97, 140-151.

https://doi.org/10.1016/j.neuropsychologia.2017.02.008

Devolder, P. A., Brigham, M. C., \& Pressley, M. (1990). Memory performance awareness in younger and older adults. Psychology and Aging, 5(2), 291-303.

https://doi.org/10.1037//0882-7974.5.2.291

Dunlosky, J., Bailey, H., \& Hertzog, C. (2011). Memory enhancement strategies: What works best for obtaining memory goals? In P. Hartman-Stein \& A. LaRue (Eds.), Enhancing Cognitive Fitness in Adults (pp. 3-23). Springer. https://doi.org/10.1007/978-1-44190636-6_1

Dunlosky, J., \& Metcalfe, J. (2009). Metacognition. Sage.

Dunn, T. L., \& Risko, E. F. (2016). Toward a metacognitive account of cognitive offloading. Cognitive Science, 40(5), 1080-1127. https://doi.org/10.1111/cogs.12273

Einstein, G. O., \& McDaniel, M. A. (1990). Normal aging and prospective memory. Journal of Experimental Psychology. Learning, Memory, and Cognition, 16(4), 717-726. https://doi.org/10.1037/0278-7393.16.4.717

Ellis, J. (1996). Prospective memory or the realization of delayed intentions: A conceptual framework for research. In M. A. Brandimonte, G. O. Einstein, \& M. A. McDaniel (Eds.), Prospective Memory: Theory and Applications (pp. 1-22). Erlbaum.

Gilbert, S. J. (2015a). Strategic offloading of delayed intentions into the external environment. Quarterly Journal of Experimental Psychology, 68(5), 971-992. https://doi.org/10.1080/17470218.2014.972963

Gilbert, S. J. (2015b). Strategic use of reminders: Influence of both domain-general and taskspecific metacognitive confidence, independent of objective memory ability. Consciousness and Cognition, 33, 245-260. 
https://doi.org/10.1016/j.concog.2015.01.006

Graf, P., \& Uttl, B. (2001). Prospective Memory: A New Focus for Research. Consciousness and Cognition, 10(4), 437-450. https://doi.org/10.1006/ccog.2001.0504

Hayes, A. F. (2018). Introduction to Mediation, Moderation, and Conditional Process Analysis: A Regression-Based Approach (2nd ed.). The Guilford Press.

Hering, A., Phillips, L. H., \& Kliegel, M. (2013). Importance effects on age differences in performance in event-based prospective memory. Gerontology, 60(1), 73-78. https://doi.org/10.1159/000355057

Hertzog, C. (2016). Aging and Metacognitive Control. In J. Dunlosky \& S. K. Tauber (Eds.), The Oxford Handbook of Metamemory (pp. 537-558). Oxford University Press. https://doi.org/10.1093/OXFORDHB/9780199336746.013.31

Hertzog, C., \& Dunlosky, J. (2011). Metacognition in later adulthood: Spared monitoring can benefit older adults' self-regulation. Current Directions in Psychological Science, 20(3), 167-173. https://doi.org/10.1177/0963721411409026

Hertzog, C., \& Hultsch, D. F. (2000). Metacognition in adulthood and old age. In I. M. Craik \& T. A. Salthouse (Eds.), The handbook of aging and cognition (pp. 417-466). Lawrence Erlbaum Associates Publishers.

Hertzog, C., Lustig, E., Pearman, A., \& Waris, A. (2019). Behaviors and strategies supporting everyday memory in older adults. Gerontology, 65(4), 419-429. https://doi.org/10.1159/000495910

Hu, X., Luo, L., \& Fleming, S. M. (2019). A role for metamemory in cognitive offloading. Cognition, 193, 104012. https://doi.org/10.1016/j.cognition.2019.104012

Hultsch, D. F., Hertzog, C., \& Dixon, R. A. (1987). Age differences in metamemory: Resolving the inconsistencies. Canadian Journal of Psychology, 41(2), 193-208. https://doi.org/10.1037/h0084153 
Hummert, M. L. (2011). Age stereotypes and aging. Handbook of the Psychology of Aging, 249-262. https://doi.org/10.1016/B978-0-12-380882-0.00016-4

Ihle, A., Hering, A., Mahy, C. E. V., Bisiacchi, P. S., \& Kliegel, M. (2013). Adult age differences, response management, and cue focality in event-based prospective memory: A meta-analysis on the role of task order specificity. Psychology and Aging, 28(3), 714720. https://doi.org/10.1037/a0033653

Jennings, J. M., \& Darwin, A. L. (2003). Efficacy beliefs, everyday behavior, and memory performance among older elderly adults. Educational Gerontology, 29(1), 71-91. https://doi.org/10.1080/713844231

Kliegel, M., Jäger, T., \& Phillips, L. H. (2008). Adult age differences in event-based prospective memory: A meta-analysis on the role of focal versus nonfocal cues. Psychology and Aging, 23(1), 203-208. https://doi.org/10.1037/0882-7974.23.1.203

Kornadt, A. E., \& Rothermund, K. (2012). Internalization of age stereotypes into the selfconcept via future self-views: A general model and domain-specific differences. Psychology and Aging, 27(1), 164-172. https://doi.org/10.1037/a0025110

Kroenke, K., Spitzer, R. L., \& Williams, J. B. W. (2001). The PHQ-9. Journal of General Internal Medicine, 16(9), 606-613. https://doi.org/10.1046/j.15251497.2001.016009606.x

Kuhlmann, B. G., \& Touron, D. R. (2012). Mediator-based encoding strategies in source monitoring in young and older adults. Journal of Experimental Psychology: Learning Memory and Cognition, 38(5), 1352-1364. https://doi.org/10.1037/a0027863

Lemaire, P., Arnaud, L., \& Lecacheur, M. (2004). Adults' age-related differences in adaptivity of strategy choices: Evidence from computational estimation. Psychology and Aging, 19(3), 467-481. https://doi.org/10.1037/0882-7974.19.3.467

Lemaire, P., \& Lecacheur, M. (2001). Older and younger adults' strategy use and execution 
in currency conversion tasks: Insights from French franc to euro and euro to French franc conversions. Journal of Experimental Psychology. Applied, 7(3), 195-206. http://www.ncbi.nlm.nih.gov/pubmed/11676098

Levy, B. R., \& Leifheit-Limson, E. (2009). The stereotype-matching effect: Greater influence on functioning when age stereotypes correspond to outcomes. Psychology and Aging, 24(1), 230-233. https://doi.org/10.1037/a0014563

Lindenberger, U., \& Mayr, U. (2014). Cognitive aging: Is there a dark side to environmental support? Trends in Cognitive Sciences, 18(1), 7-15. https://doi.org/10.1016/j.tics.2013.10.006

Loewen, E. R., Shaw \& Fergus, R. J., \& Craik, I. M. (1990). Age differences in components of metamemory. Experimental Aging Research, 16(1), 43-48. https://doi.org/10.1080/03610739008253873

Lovelace, E. A., \& Twohig, P. T. (1990). Healthy older adults' perceptions of their memory functioning and use of mnemonics. Bulletin of the Psychonomic Society, 28(2), 115118. https://doi.org/10.3758/BF03333979

Masumoto, K., Nishimura, C., Tabuchi, M., \& Fujita, A. (2011). What factors influence prospective memory for elderly people in a naturalistic setting? Japanese Psychological Research, 53(1), 30-41. https://doi.org/10.1111/j.1468-5884.2010.00453.x

Maylor, E. A. (1996). Age-related impairment in an event-based prospective-memory task. Psychology and Aging, 11(1), 74-78. https://doi.org/10.1037//0882-7974.11.1.74

Maylor, E. A. (2008). Commentary: Prospective memory through the ages. In M. Kliegel, M. A. McDaniel, \& G. O. Einstein (Eds.), Prospective memory: Cognitive, neuroscience, developmental, and applied perspectives (pp. 217-233). Erlbaum.

McGillivray, S., \& Castel, A. D. (2017). Older and younger adults' strategic control of metacognitive monitoring: The role of consequences, task experience, and prior 
knowledge. Experimental Aging Research, 43(3), 233-256.

https://doi.org/10.1080/0361073X.2017.1298956

Molden, J., \& Maxfield, M. (2017). The impact of aging stereotypes on dementia worry. European Journal of Ageing, 14(1), 29-37. https://doi.org/10.1007/s10433-016-0378-z

Nasreddine, Z. S., Phillips, N. A., Bédirian, V., Charbonneau, S., Whitehead, V., Collin, I., Cummings, J. L., \& Chertkow, H. (2005). The Montreal Cognitive Assessment, MoCA: A brief screening tool for mild cognitive impairment. Journal of the American Geriatrics Society, 53(4), 695-699. https://doi.org/10.1111/j.1532-5415.2005.53221.x

Naveh-Benjamin, M., Brav, T. K., \& Levy, O. (2007). The associative memory deficit of older adults: The role of strategy utilization. Psychology and Aging, 22(1), 202-208. https://doi.org/10.1037/0882-7974.22.1.202

Nelson, H. E., \& Willison, J. (1991). The National Adult Reading Test (NART). NFERNelson.

Nelson, T. O., \& Narens, L. (1990). Metamemory: A theoretical framework and new findings. Psychology of Learning and Motivation, 26, 125-173. https://doi.org/10.1016/s0079-7421(08)60053-5

Ng, A. R. J. (2017). Metacognition in Prospective Memory [Doctoral thesis, University of Western Australia]. https://doi.org/10.4225/23/59c9f9441e58d

Park, D. C., Hertzog, C., Kidder, D. P., Morrell, R. W., \& Mayhorn, C. B. (1997). Effect of age on event-based and time-based prospective memory. Psychology and Aging, 12(2), 314-327. https://doi.org/10.1037//0882-7974.12.2.314

Park, D. C., \& Reuter-Lorenz, P. (2009). The adaptive brain: Aging and neurocognitive scaffolding. Annual Review of Psychology, 60(1), 173-196. https://doi.org/10.1146/annurev.psych.59.103006.093656

Phillips, L. H., Henry, J. D., \& Martin, M. (2008). Adult aging and prospective memory: The 
importance of ecological validity. In M. Kliegel, M. A. McDaniel, \& G. O. Einstein (Eds.), Prospective memory: Cognitive, neuroscience, developmental, and applied perspectives (pp. 161-185). Erlbaum.

Raven, J., Raven, J. C., \& Court, J. H. (1998). Manual for Raven's progressive matrices and vocabulary scales. Oxford Psychologists Press.

Redshaw, J., Vandersee, J., Bulley, A., \& Gilbert, S. J. (2018). Development of children's use of external reminders for hard-to-remember intentions. Child Development, 89(6), 2099-2108. https://doi.org/10.1111/cdev.13040

Reuter-Lorenz, P. A., \& Park, D. C. (2014). How does it STAC up? Revisiting the scaffolding theory of aging and cognition. Neuropsychology Review, 24(3), 355-370. https://doi.org/10.1007/s11065-014-9270-9

Risko, E. F., \& Dunn, T. L. (2015). Storing information in-the-world: Metacognition and cognitive offloading in a short-term memory task. Consciousness and Cognition, 36, 61-74. https://doi.org/10.1016/j.concog.2015.05.014

Risko, E. F., \& Gilbert, S. J. (2016). Cognitive Offloading. Trends in Cognitive Sciences, 20(9), 676-688. https://doi.org/10.1016/J.TICS.2016.07.002

Rose, N. S., Rendell, P. G., McDaniel, M. A., Aberle, I., \& Kliegel, M. (2010). Age and individual differences in prospective memory during a "virtual week": The roles of working memory, vigilance, task regularity, and cue focality. Psychology and Aging, 25(3), 595-605. https://doi.org/10.1037/a0019771

Rummel, J., Danner, D., \& Kuhlmann, B. G. (2019). The short version of the Metacognitive Prospective Memory Inventory (MPMI-s): Factor structure, reliability, validity, and reference data. Measurement Instruments for the Social Sciences, 1(1), 1-8. https://doi.org/10.1186/s42409-019-0008-6

Scarampi, C., \& Gilbert, S. J. (2020). The effect of recent reminder setting on subsequent 
strategy and performance in a prospective memory task. Memory, 28(5), 677-691. https://doi.org/10.1080/09658211.2020.1764974

Schillemans, V., Luwel, K., Ceulemans, E., Onghena, P., \& Verschaffel, L. (2012). The effect of single versus repeated previous strategy use on individuals' subsequent strategy choice. Psychologica Belgica, 52(4), 307-325. https://doi.org/10.5334/pb-52-4-307

Schnitzspahn, K. M., Ihle, A., Henry, J. D., Rendell, P. G., \& Kliegel, M. (2011). The ageprospective memory-paradox: An exploration of possible mechanisms. International Psychogeriatrics, 23(4), 583-592. https://doi.org/10.1017/S1041610210001651

Schnitzspahn, K. M., Stahl, C., Zeintl, M., Kaller, C. P., \& Kliegel, M. (2013). The role of shifting, updating, and inhibition in prospective memory performance in young and older adults. Developmental Psychology, 49(8), 1544-1553. https://doi.org/10.1037/a0030579

Schryer, E., \& Ross, M. (2013). The use and benefits of external memory aids in older and younger adults. Applied Cognitive Psychology, 27(5), 663-671. https://doi.org/10.1002/acp.2946

Smith, R. E. (2003). The cost of remembering to remember in event-based prospective memory: Investigating the capacity demands of delayed intention performance. Journal of Experimental Psychology: Learning, Memory, and Cognition, 29(3), 347-361. https://doi.org/10.1037/0278-7393.29.3.347

Touron, D. R., Oransky, N., Meier, M. E., \& Hines, J. C. (2010). Metacognitive monitoring and strategic behaviour in working memory performance. Quarterly Journal of Experimental Psychology, 63(8), 1533-1551. https://doi.org/10.1080/17470210903418937

Uttl, B. (2008). Transparent meta-analysis of prospective memory and aging. PLoS ONE, 3(2), e1568. https://doi.org/10.1371/journal.pone.0001568 
Weakley, A., Weakley, A. T., \& Schmitter-Edgecombe, M. (2019). Compensatory strategy use improves real-world functional performance in community dwelling older adults. Neuropsychology, 33(8), 1121-1135. https://doi.org/10.1037/neu0000591

West, R. L., Bagwell, D. K., \& Dark-Fredeman, A. (2008). Self-efficacy and memory aging: The impact of a memory intervention based on self-efficacy. Aging, Neuropsychology, and Cognition, 15(3), 302-329. https://doi.org/10.1080/13825580701440510

Zuber, S., Ihle, A., Blum, A., Desrichard, O., \& Kliegel, M. (2019). The effect of stereotype threat on age differences in prospective memory performance: Differential effects on focal versus nonfocal tasks. The Journals of Gerontology: Series B, 74(4), 625-632. https://doi.org/10.1093/geronb/gbx097 


\section{INTENTION OFFLOADING AND AGEING}

Table 1.

$F$-values, significance levels and partial eta-square for objective accuracy, predicted accuracy and metacognitive bias in the intention-offloading task

\begin{tabular}{|c|c|c|c|c|c|c|}
\hline & \multicolumn{2}{|c|}{$\begin{array}{l}\text { Objective } \\
\text { accuracy }\end{array}$} & \multicolumn{2}{|c|}{$\begin{array}{l}\text { Predicted } \\
\text { accuracy }\end{array}$} & \multicolumn{2}{|c|}{$\begin{array}{c}\text { Metacognitive } \\
\text { bias }\end{array}$} \\
\hline & $F(1,86)$ & $\eta_{p 2}$ & $F(1,86)$ & $\eta_{p 2}$ & $F(1,86)$ & $\eta_{p 2}$ \\
\hline $\begin{array}{l}\text { Age group } \\
\text { (younger vs. older) }\end{array}$ & $10.88^{* *}$ & .11 & 1.32 & .02 & 2.69 & .03 \\
\hline $\begin{array}{l}\text { Memory load } \\
\text { (1-target vs. 3- } \\
\text { targets) }\end{array}$ & $31.76 * * *$ & .27 & $39.82^{* * *}$ & .32 & 0.01 & $<.01$ \\
\hline $\begin{array}{l}\text { Offloading } \\
\text { (no reminders vs. } \\
\text { optional reminders) }\end{array}$ & $16.57 * * *$ & .16 & 1.44 & .02 & $7.83^{* *}$ & .08 \\
\hline $\begin{array}{l}\text { Age group } \mathrm{x} \\
\text { Memory load }\end{array}$ & $11.62 * * *$ & .12 & 0.15 & $<.01$ & $5.05 *$ & .06 \\
\hline $\begin{array}{l}\text { Age group } \mathrm{x} \\
\text { Offloading }\end{array}$ & $3.55 \#$ & .04 & $4.95 *$ & .05 & $7.07 * *$ & .08 \\
\hline $\begin{array}{l}\text { Memory load x } \\
\text { Offloading }\end{array}$ & $4.89 *$ & .05 & $9.87 * *$ & .10 & 0.04 & $<.01$ \\
\hline $\begin{array}{l}\text { Age group x } \\
\text { Memory load x } \\
\text { Offloading }\end{array}$ & 0.76 & .01 & $5.75 *$ & .06 & 0.34 & $<.01$ \\
\hline
\end{tabular}

Note. $\# p<.1 ; * p<.05 ; * * p<.01 ; * * * p<.001$. 
Table 2.

F-values, significance levels and partial eta-square for objective accuracy, predicted accuracy and metacognitive bias in the intention-offloading task, separated by memory load condition

\begin{tabular}{|c|c|c|c|c|c|c|c|c|c|c|c|c|}
\hline & \multicolumn{4}{|c|}{ Objective accuracy } & \multicolumn{4}{|c|}{ Predicted accuracy } & \multicolumn{4}{|c|}{ Metacognitive bias } \\
\hline & \multicolumn{2}{|c|}{1 target } & \multicolumn{2}{|c|}{3 targets } & \multicolumn{2}{|c|}{1 target } & \multicolumn{2}{|c|}{3 targets } & \multicolumn{2}{|c|}{1 target } & \multicolumn{2}{|c|}{3 targets } \\
\hline & $F(1,86)$ & $\eta_{p 2}$ & $F(1,86)$ & $\eta_{p 2}$ & $F(1,86)$ & $\eta_{p 2}$ & $F(1,86)$ & $\eta_{p 2}$ & $F(1,86)$ & $\eta_{p 2}$ & $F(1,86)$ & $\eta_{p 2}$ \\
\hline $\begin{array}{l}\text { Age group } \\
\text { (younger vs. older) }\end{array}$ & 1.19 & .01 & $17.48^{* * *}$ & .17 & 1.25 & .01 & 0.94 & .01 & 0.03 & $<.01$ & $5.26 *$ & .06 \\
\hline $\begin{array}{l}\text { Offloading } \\
\text { (no reminders vs. } \\
\text { optional reminders) }\end{array}$ & $3.71 \#$ & .04 & $15.52^{* * *}$ & 0.15 & $3.94 *$ & .04 & $5.84 *$ & .06 & $6.43 *$ & .07 & 3.87 & .04 \\
\hline $\begin{array}{l}\text { Age group x } \\
\text { Offloading }\end{array}$ & 1.02 & .01 & $3.01 \#$ & .03 & $25.07 * * *$ & .23 & $<.01$ & $<.01$ & $9.05 * *$ & .10 & 2.11 & .02 \\
\hline
\end{tabular}

Note. $\# p<.1 ; * p<.05 ; * * p<.01 ; * * * p<.001$.

Table 3.

F-values, significance levels and partial eta-square for objective accuracy, predicted accuracy and metacognitive bias in the intention-offloading task, separated by offloading condition

\begin{tabular}{|c|c|c|c|c|c|c|c|c|c|c|c|c|}
\hline & \multicolumn{4}{|c|}{ Objective accuracy } & \multicolumn{4}{|c|}{ Predicted accuracy } & \multicolumn{4}{|c|}{ Metacognitive bias } \\
\hline & \multicolumn{2}{|c|}{ No reminders } & \multicolumn{2}{|c|}{$\begin{array}{l}\text { Optional } \\
\text { reminders }\end{array}$} & \multicolumn{2}{|c|}{ No reminders } & \multicolumn{2}{|c|}{$\begin{array}{l}\text { Optional } \\
\text { reminders }\end{array}$} & \multicolumn{2}{|c|}{ No reminders } & \multicolumn{2}{|c|}{$\begin{array}{l}\text { Optional } \\
\text { reminders }\end{array}$} \\
\hline & $F(1,86)$ & $\eta_{p 2}$ & $F(1,86)$ & $\eta_{p 2}$ & $F(1,86)$ & $\eta_{p 2}$ & $F(1,86)$ & $\eta_{p 2}$ & $F(1,86)$ & $\eta_{p 2}$ & $F(1,86)$ & $\eta_{p 2}$ \\
\hline $\begin{array}{l}\text { Age group } \\
\text { (younger vs. older) }\end{array}$ & $11.33^{* *}$ & .12 & 2.28 & .03 & $<.01$ & $<.01$ & $4.08 *$ & .05 & $7.36 * *$ & .08 & 0.11 & $<.01$ \\
\hline $\begin{array}{l}\text { Memory load } \\
\text { (1-target vs. 3- } \\
\text { targets) }\end{array}$ & $21.13^{* * *}$ & .20 & $6.16 *$ & .07 & $39.58 * * *$ & .32 & $10.43^{* *}$ & .11 & 0.01 & $<.01$ & 0.04 & $<.01$ \\
\hline $\begin{array}{l}\text { Age group x } \\
\text { Memory load }\end{array}$ & $6.14 *$ & .07 & 3.77\# & .04 & 2.76 & .03 & 1.84 & .02 & 1.17 & .01 & $5.66 *$ & .06 \\
\hline
\end{tabular}

Note. $\# p<.1 ; * p<.05 ; * * p<.01 ; * * p<.001$. 
Table 4.

Sample descriptives and independent samples t-tests comparing the accuracy measures in the two age groups

\begin{tabular}{|c|c|c|c|c|c|c|c|}
\hline & & \multicolumn{2}{|c|}{ Younger adults } & \multicolumn{2}{|c|}{ Older adults } & \multirow[b]{2}{*}{$t$-test $(1,86)$} & \multirow[b]{2}{*}{$d$} \\
\hline & & $M$ & $S D$ & $M$ & $S D$ & & \\
\hline \multirow{4}{*}{ Objective Accuracy } & 1 target, no reminders & 92.27 & 13.79 & 87.80 & 17.87 & 1.31 & .28 \\
\hline & 3 targets, no reminders & 87.12 & 18.49 & 70.61 & 22.88 & $3.72 * * *$ & .79 \\
\hline & 1 target, optional reminders & 94.09 & 9.23 & 93.64 & 14.16 & 0.18 & .04 \\
\hline & 3 targets, optional reminders & 93.18 & 12.57 & 86.21 & 18.32 & $2.08 *$ & .44 \\
\hline \multirow{4}{*}{ Perceived Accuracy } & 1 target, no reminders & 91.73 & 8.63 & 94.57 & 8.54 & 1.55 & .33 \\
\hline & 3 targets, no reminders & 83.66 & 13.71 & 80.70 & 20.53 & 0.79 & .17 \\
\hline & 1 target, optional reminders & 94.61 & 8.43 & 87.89 & 11.34 & $3.16 * *$ & .67 \\
\hline & 3 targets, optional reminders & 88.05 & 17.84 & 85.20 & 12.50 & 0.87 & .18 \\
\hline \multirow{4}{*}{ Metacognitive Bias } & 1 target, no reminders & -0.55 & 16.60 & 6.77 & 19.94 & $1.87 \#$ & .40 \\
\hline & 3 targets, no reminders & -3.46 & 23.35 & 10.10 & 28.64 & $2.43 *$ & .52 \\
\hline & 1 target, optional reminders & 0.52 & 12.24 & -5.75 & 18.88 & $1.85 \#$ & .39 \\
\hline & 3 targets, optional reminders & -5.14 & 21.96 & -1.01 & 19.77 & 0.93 & .20 \\
\hline
\end{tabular}

Note. $\# p<.1 ; * p<.05 ; * * p<.01 ; * * * p<.001$. 
Table 5.

Correlations between measures. Results from the older group are shown in red and results from the younger group are shown in blue.

\begin{tabular}{|c|c|c|c|c|c|c|c|c|c|c|c|c|}
\hline & \multicolumn{3}{|c|}{ No Reminders } & \multicolumn{4}{|c|}{ Optional Reminders } & \multicolumn{4}{|c|}{ Questionnaires } \\
\hline & & $\begin{array}{l}\text { Objective } \\
\text { Accuracy }\end{array}$ & $\begin{array}{l}\text { Predicted } \\
\text { Accuracy }\end{array}$ & $\begin{array}{c}\text { Metacognitive } \\
\text { Bias }\end{array}$ & $\begin{array}{l}\text { Objective } \\
\text { Accuracy }\end{array}$ & $\begin{array}{l}\text { Predicted } \\
\text { Accuracy }\end{array}$ & $\begin{array}{c}\text { Metacognitive } \\
\text { Bias }\end{array}$ & $\begin{array}{l}\text { Intention } \\
\text { Offloading }\end{array}$ & $\begin{array}{l}\text { Need for } \\
\text { Cognition }\end{array}$ & PMA & PMSi & PMSe \\
\hline \multirow{3}{*}{ 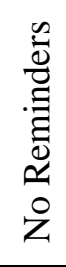 } & $\begin{array}{l}\text { Objective } \\
\text { Accuracy }\end{array}$ & - & .10 & $-.77^{* * * * *}$ & .17 & .15 & -.04 & -.02 & .07 & .19 & $.42 * *$ & .19 \\
\hline & $\begin{array}{l}\text { Predicted } \\
\text { Accuracy }\end{array}$ & -.08 & - & $.55 * * *$ & $<-.01$ & $.65^{\text {*** }}$ & $.42 * *$ & $-.33 *$ & $.49 * * *$ & -.07 & .02 & .22 \\
\hline & $\begin{array}{c}\text { Metacognitive } \\
\text { Bias }\end{array}$ & $-.82 * * * *$ & $.64 * * *$ & - & -.14 & $.29 \#$ & $.30 *$ & -.19 & .25 & -.20 & $-.34 *$ & -.02 \\
\hline \multirow{4}{*}{ 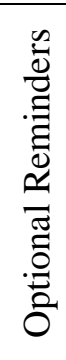 } & $\begin{array}{l}\text { Objective } \\
\text { Accuracy }\end{array}$ & .22 & .18 & -.07 & - & .05 & $-.76 * * * *$ & $.36 *$ & .15 & -.13 & .19 & .09 \\
\hline & $\begin{array}{l}\text { Predicted } \\
\text { Accuracy }\end{array}$ & .10 & $.53 * * *$ & .23 & .10 & - & $.61 * * *$ & $-.34 *$ & $.45^{* * *}$ & -.05 & -.07 & .18 \\
\hline & $\begin{array}{c}\text { Metacognitive } \\
\text { Bias }\end{array}$ & -.06 & $.32 *$ & .23 & $-.57 * * *$ & $.76^{* * * *}$ & - & -.50 *** & .17 & .07 & -.19 & .05 \\
\hline & $\begin{array}{l}\text { Intention } \\
\text { Offloading }\end{array}$ & .08 & -.04 & -.09 & .34 & -.07 & $-.28 \#$ & - & -.25 & -.21 & .21 & $.30 *$ \\
\hline \multirow{4}{*}{ 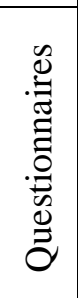 } & $\begin{array}{l}\text { Need for } \\
\text { Cognition }\end{array}$ & -.08 & -.03 & .04 & -.09 & .11 & .15 & -.14 & - & .06 & -.13 & -.11 \\
\hline & PMA & .05 & -.02 & -.05 & -.05 & -.02 & .02 & -.09 & $.36 *$ & - & .23 & -.15 \\
\hline & PMSi & .22 & .18 & -.07 & .09 & .09 & .02 & .18 & .14 & $.36 *$ & - & $.45 * *$ \\
\hline & PMSe & -.04 & .05 & .06 & .15 & .20 & .06 & .09 & $.47 * *$ & .15 & $.28 \#$ & - \\
\hline
\end{tabular}

Note. $\# p<.1 ; * p<.05 ; * * p<.01 ; * * * p<.001$. PMA = Prospective Memory Ability scale, Metacognitive prospective memory inventory; PMSi $=$ Prospective Memory internal Strategies scale, Metacognitive prospective memory inventory; PMSe = Prospective Memory external Strategies scale, Metacognitive prospective memory inventory. 
A: Instructions

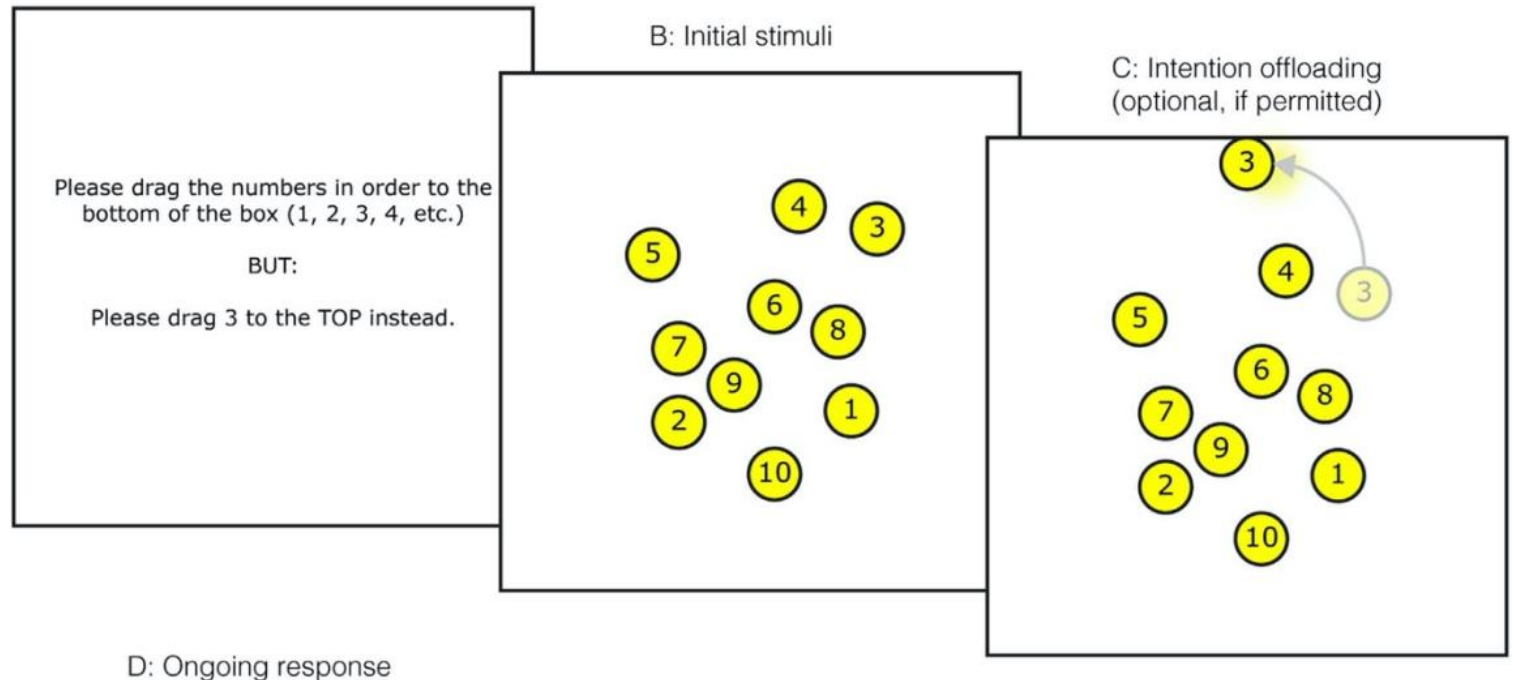

D: Ongoing response

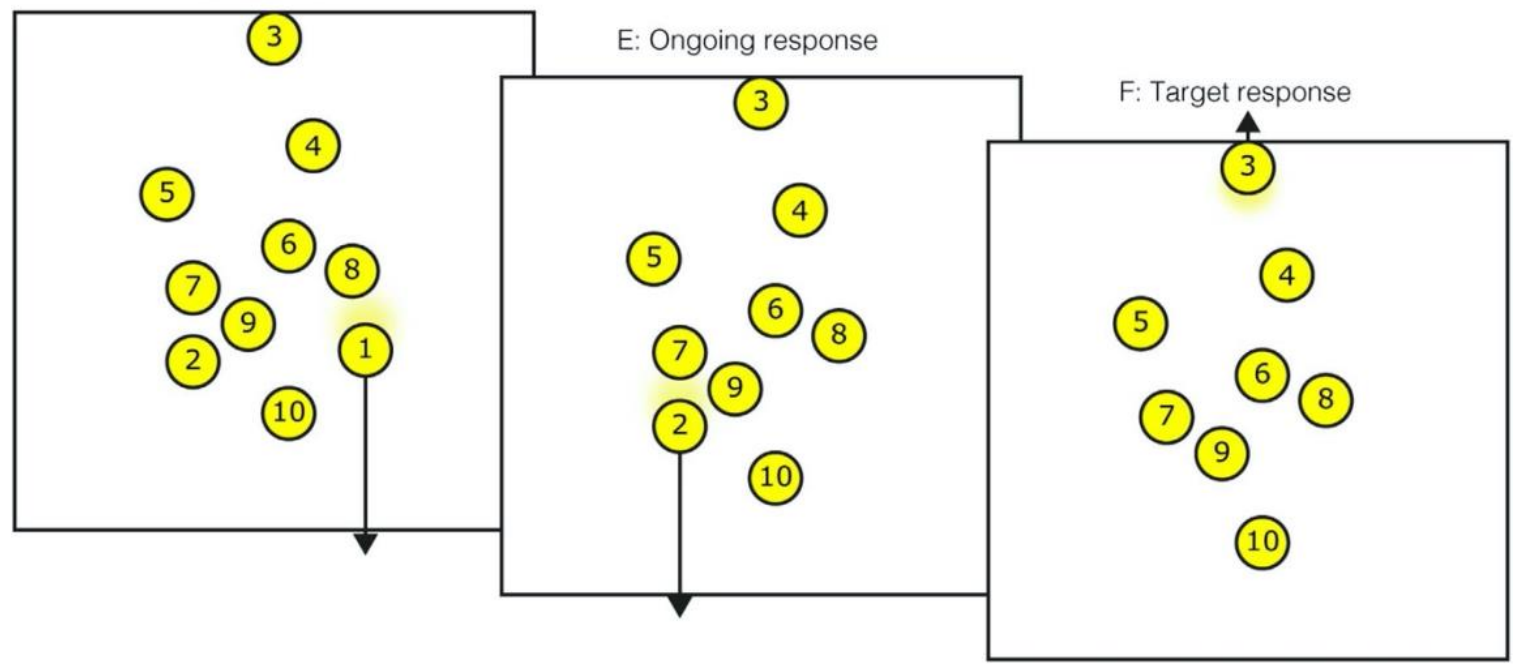

Figure 1. Schematic illustration of the intention-offloading task. 


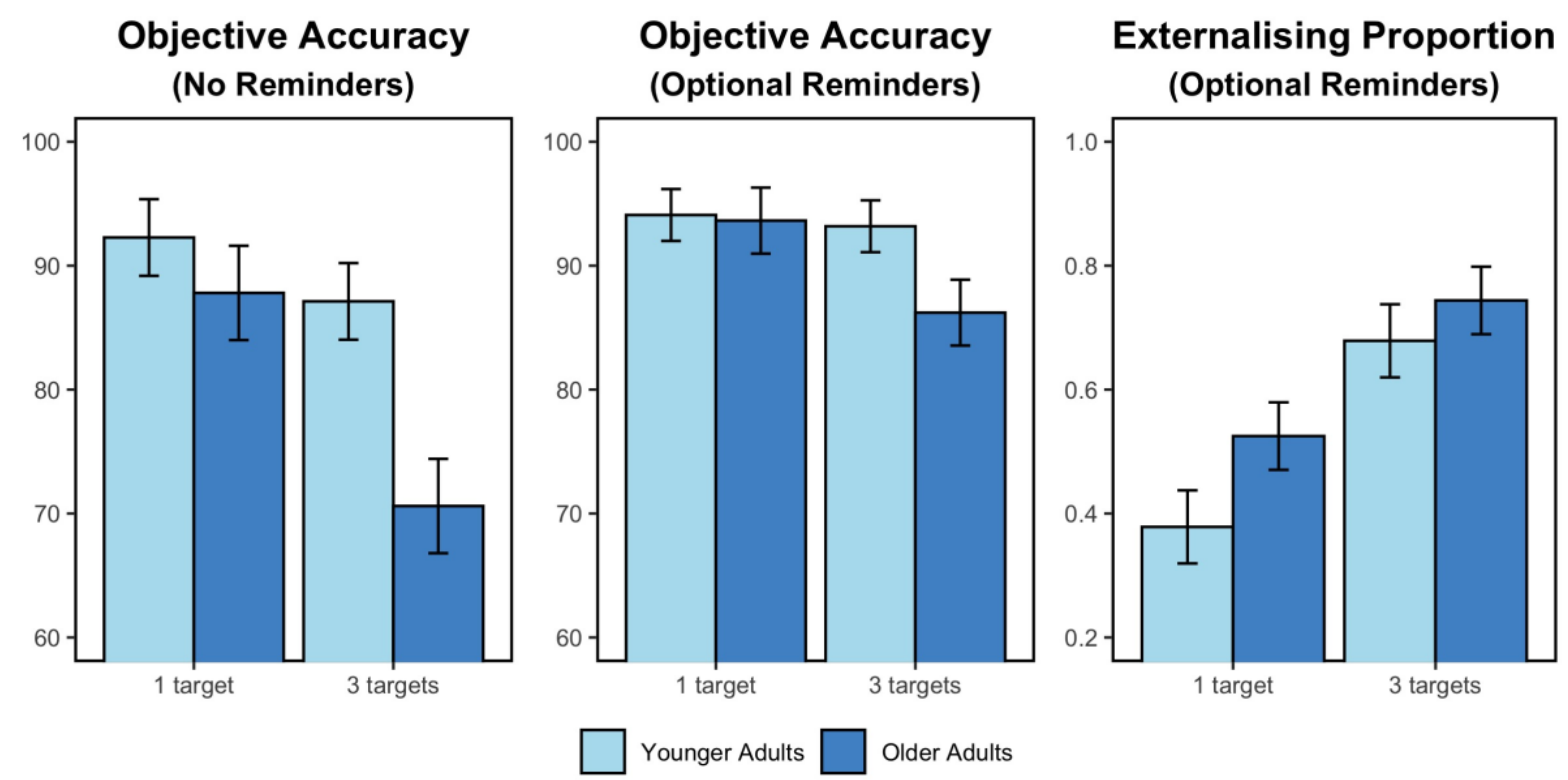

Figure 2. Results from the intention offloading task: accuracy measures and intention offloading. Error bars indicate 95\% CI for the within-subject comparison between 1-target and 3-target conditions, such that nonoverlapping bars indicate a significant difference between means. 
A) Predicted Accuracy (\%)
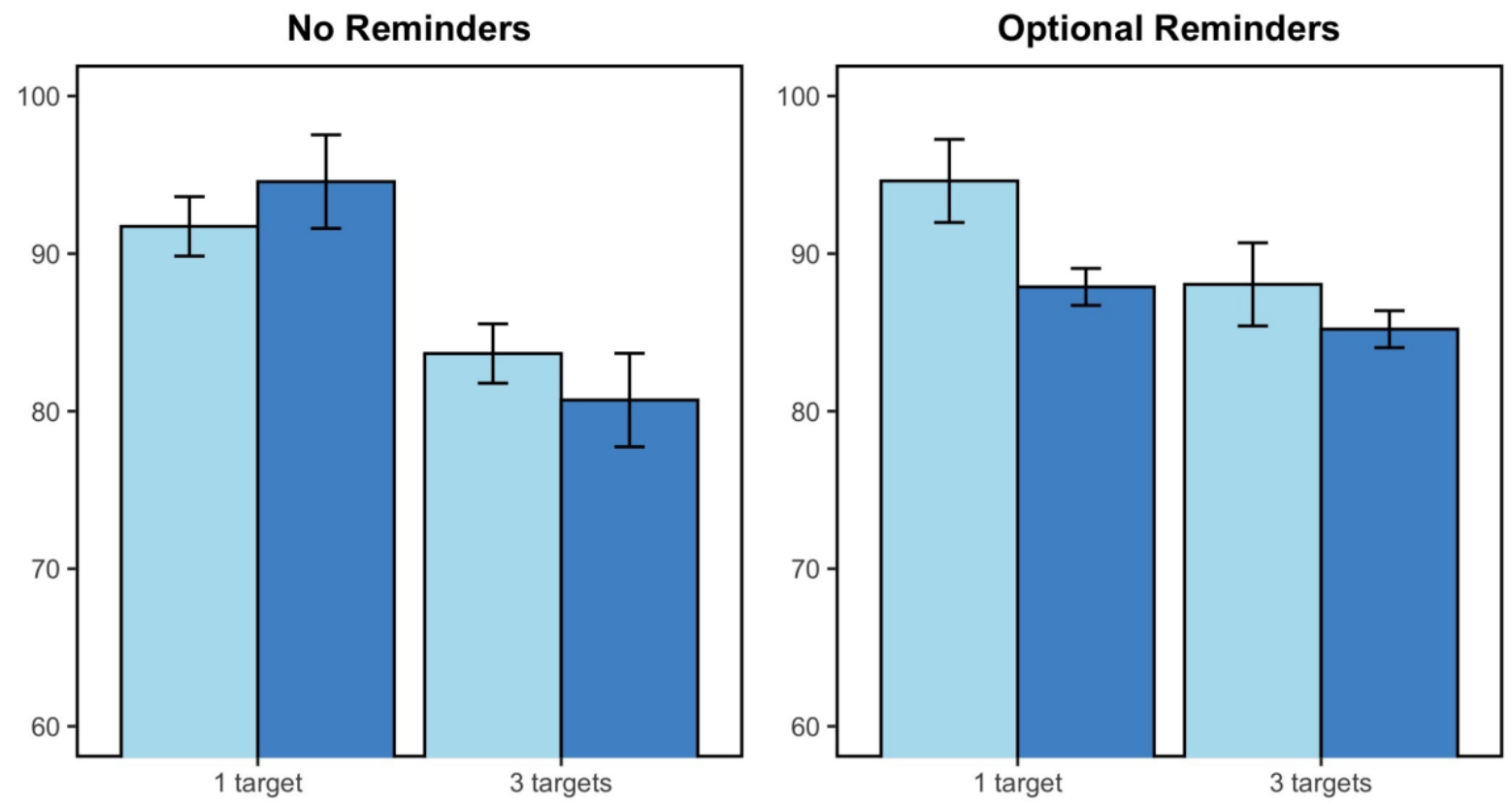

B) Metacognitive Bias

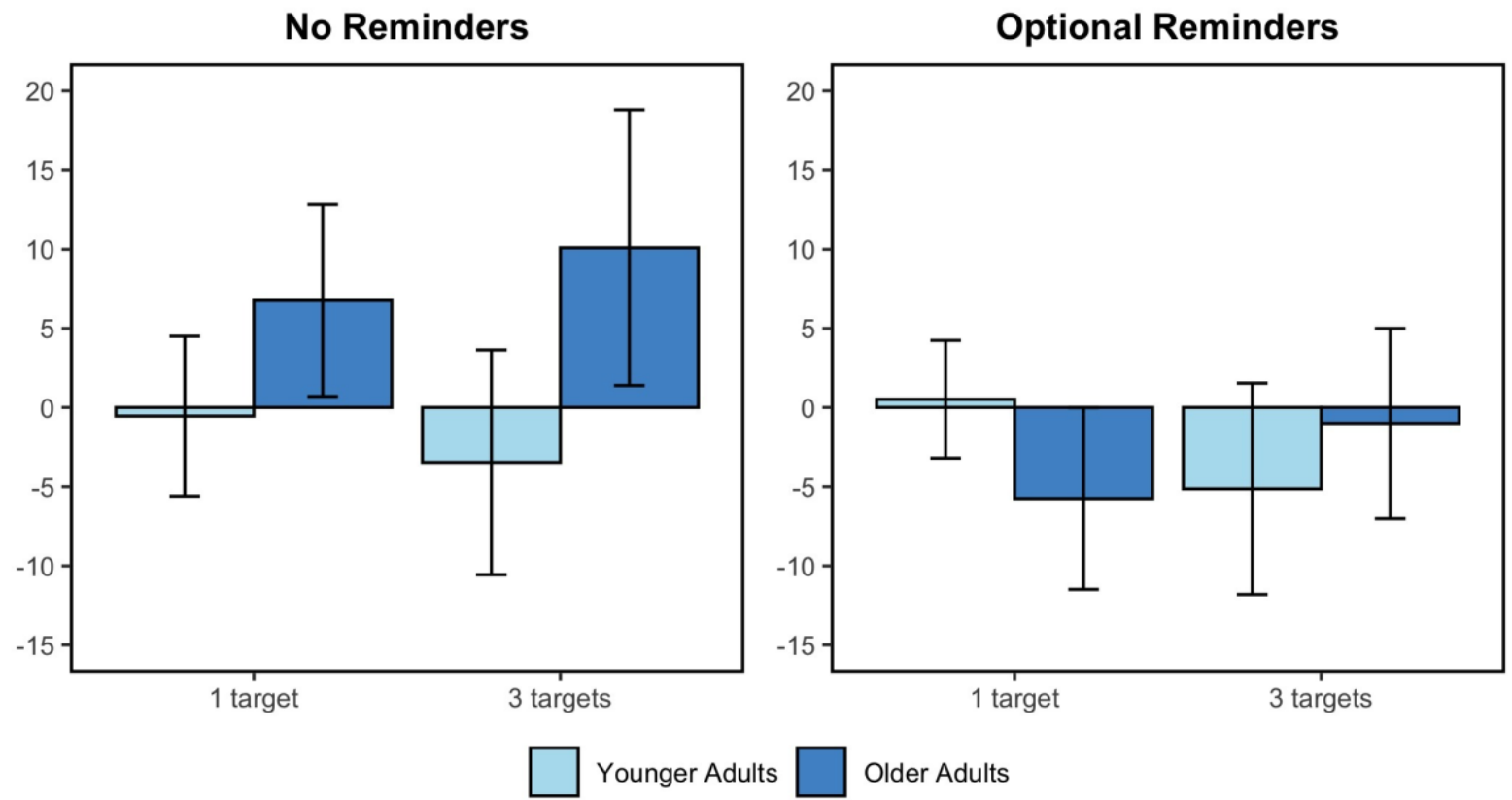

Figure 3. Results from the intention offloading task: metacognitive measures. A) Error bars for predicted accuracy indicate 95\% CI for the within-subject comparison between 1-target and 3-target conditions, such that nonoverlapping bars indicate a significant difference between means. B) A positive value indicates overconfidence and a negative value underconfidence. Error bars for metacognitive bias represent $95 \% \mathrm{CI}$ for the comparison against zero, such that a bar not crossing zero indicates a significant bias. 